Article

\title{
Mediating Factor of Emotional Intelligence in Intercultural Competence and Work Productivity of Volunteers
}

\author{
Jolita Vveinhardt *, Rita Bendaraviciene and Ingrida Vinickyte \\ Department of Management, Faculty of Economics and Management, Vytautas Magnus University, \\ S. Daukanto Str. 28, LT-44246 Kaunas, Lithuania; rita.bendaraviciene@vdu.lt (R.B.); \\ vinickyte.in@gmail.com (I.V.) \\ * Correspondence: jolita.vveinhardt@gmail.com; Tel.: +370-698-06668
}

Received: 10 March 2019; Accepted: 1 May 2019; Published: 7 May 2019

\begin{abstract}
Volunteering, the volunteer's intercultural competence and emotional intelligence contribute to intercultural education and sustainability in various societies of today. The aim of this study was to analyse the impact of emotional intelligence and intercultural competence on work productivity of volunteers. The first part of the article substantiates theoretical associations between emotional intelligence, intercultural competence and work productivity. Based on theoretical insights, empirical research methodology was prepared, which consisted of four categories divided into sub-categories that provided the structure of the question groups. The empirical research involved seven informants working in Lithuania, who welcomed volunteers from abroad. The research was conducted using the method of semi-structured interviews. The conclusions present a systematic perspective towards the role of emotional intelligence in the intercultural competence and work productivity of volunteers. In this context, emotional intelligence works as a mediating factor. The contributing role of volunteer-receiving organisations in the development of the volunteers' emotional intelligence is also highlighted.
\end{abstract}

Keywords: volunteer; volunteering; emotional intelligence; culture shock; intercultural competence; work productivity; sustainability; Lithuania

\section{Introduction}

Often, sustainability in society is associated with a voluntary initiative. However, volunteering, especially in areas orientated to the weakest members of society, is a significant contribution to sustainability and welfare. All of it promotes to focus on the development of volunteers' emotional and intercultural competencies. According to Goleman, the development of emotional intelligence starts in early childhood, when even the smallest interactions of children with their parents, teachers and each other contain emotional information. Over the recent years, there have been increasing numbers of young people who go abroad to volunteer but then encounter a culture they are not very familiar with, which causes numerous challenges and significant stress to the volunteers themselves, affecting the productivity of their work/activities. Furthermore, certain intercultural competence requirements are applied to volunteers, whereas the significance of emotional intelligence is underestimated (e.g., knowledge of a foreign language(s)). Working abroad in an intercultural environment, the volunteer comes to a new, often largely unfamiliar country where he or she faces various difficulties, culture shock being among the first ones [1]. According to Furham [2], culture shock is often associated with emotional reaction to a new culture, which affects people to a varying degree [2]. Although the emotional response is only one of the components of cultural shock, its significance is particularly 
high. The response to the experienced culture shock demonstrates the level of one's intercultural competence, while emotional reaction could be associated with emotional intelligence, which includes the ability to understand and recognize emotions: especially the ability to manage and control them for the purpose of achieving the desired result. However, another question arises as to whether the link between emotional intelligence and intercultural competence has an impact on the productivity of the volunteers' work/activities. For instance, if the emotional intelligence of a volunteer who came to a new country is low, does this affect the productivity of his/her work/activities? Scientists [1,3-9] have analysed what is required in order to ensure that volunteer activities are productive and that the work is beneficial not only to the volunteer personally but also the organization and the local community [3-9]. However, no clear correlation has been found between emotional intelligence, intercultural competence and work productivity, while volunteering abroad. The aim of the research was to analyse the impact of emotional intelligence and intercultural competence on work productivity of volunteers. For this reason, the problem of the research is raised by the following question: What is the significance of emotional intelligence and intercultural competence to volunteer activities and how can the development level of these factors impact work productivity?

The theoretical section of the study was prepared using the methods of analysis, systematization, chronology and comparison. The empirical section of the research was completed interviewing persons who work with volunteers, employing semi-structured interviews. Only people who work with volunteers in Lithuania were interviewed in this research. Data was processed using the method of qualitative content analysis.

\section{Theoretical Justification}

First, we will briefly review the scientific contributions of the last thirty years in the field of intercultural competence and emotional intelligence, considering their impact on productivity of work/activities, to see general trends. This overview does not aim to provide a detailed problem analysis; however, it could be an informative guide to the general perspective on the situation. The analysis of publications available in the Web of Science (WoS) Core Collection (Clarivate Analytics), found using the search options "by topic" and "by title", revealed the following tendencies (1990-2019): emotional intelligence (EI) research has been published in 1285 and 132 sources (by topic and title, respectively); intercultural competence (IC) research was encountered in 2123 sources during the search by the topic and in 567 sources while searching by the title. While analysing the research published solely in this database, it is evident that emotional intelligence studies have still been rather scarce, compared to the number of inquiries into intercultural competence. Work productivity research can be analysed from various angles, often while using other equivalents of this term as well. Nevertheless, when the phrase "work productivity" was used in the search, 33,885 (by topic) and 1473 (by title) sources were found. The number of volunteering studies during the analysed period was as follows: 183,503 (by topic) and 25,816 (by title). Special attention given to volunteering research is confirmed by the fact that, as early as in 1990, there were already 506 studies published on this subject, and their number kept increasing constantly and dramatically. Table 1 presents the changes in the quantity of researches on the analysed phenomena; however, it must be highlighted that this data represents only the number determined during the period of the search, because this number is constantly changing/increasing. 
Table 1. Subjects of EI, IC, WP and volunteering: changes in the quantity of researches in Web of Science (WoS) database during 1990-2018 ${ }^{1}$.

\begin{tabular}{|c|c|c|c|}
\hline $\begin{array}{l}\text { Number of Emotional } \\
\text { Intelligence Studies in WoS } \\
\text { (Year and Quantity) }\end{array}$ & $\begin{array}{l}\text { Number of Intercultural } \\
\text { Competence Studies in WoS } \\
\text { (Year and Quantity) }\end{array}$ & $\begin{array}{c}\text { Number of Work Productivity }{ }^{2} \\
\text { Studies in WoS } \\
\text { (Year and Quantity) }\end{array}$ & $\begin{array}{c}\text { Number of Volunteering }{ }^{3} \\
\text { Studies in WoS } \\
\text { (Year and Quantity) }\end{array}$ \\
\hline - & 2019 (2) & 2019 (5) & $2019(58)$ \\
\hline $2018(8)$ & 2018 (73) & 2018 (113) & 2018 (1227) \\
\hline 2017 (14) & 2017 (95) & 2017 (140) & 2017 (1346) \\
\hline $2016(5)$ & 2016 (88) & 2016 (146) & 2016 (1452) \\
\hline 2015 (9) & 2015 (96) & 2015 (121) & 2015 (1473) \\
\hline 2014 (7) & 2014 (42) & 2014 (105) & 2014 (1189) \\
\hline $2013(9)$ & 2013 (37) & 2013 (108) & 2013 (1225) \\
\hline 2012 (13) & 2012 (30) & $2012(88)$ & 2012 (1158) \\
\hline $2011(5)$ & $2011(21)$ & 2011 (76) & 2011 (1100) \\
\hline 2010 (10) & 2010 (14) & 2010 (52) & 2010 (1104) \\
\hline 2009 (9) & 2009 (13) & 2009 (84) & 2009 (1105) \\
\hline 2008 (11) & 2008 (12) & 2008 (62) & 2008 (967) \\
\hline 2007 (10) & 2007 (3) & 2007 (44) & 2007 (888) \\
\hline 2006 (3) & 2006 (5) & $2006(41)$ & 2006 (833) \\
\hline 2005 (3) & $2005(6)$ & 2005 (39) & 2005 (833) \\
\hline $2004(7)$ & $2004(4)$ & 2004 (33) & 2004 (855) \\
\hline 2003 (5) & $2003(3)$ & 2003 (26) & $2003(721)$ \\
\hline $2002(2)$ & $2002(2)$ & 2002 (18) & 2002 (711) \\
\hline- & 2001 (3) & 2001 (16) & 2001 (709) \\
\hline - & 2000 (3) & 2000 (15) & 2000 (673) \\
\hline - & 1999 (3) & 1999 (14) & 1999 (729) \\
\hline - & $1998(2)$ & 1998 (18) & 1998 (727) \\
\hline- & 1997 (1) & 1997 (13) & 1997 (693) \\
\hline 1996 (1) & 1996 (3) & 1996 (11) & 1996 (640) \\
\hline- & 1995 (2) & 1995 (12) & 1995 (634) \\
\hline 1994 (1) & 1994 (2) & $1994(9)$ & 1994 (601) \\
\hline - & $1993(1)$ & 1993 (15) & 1993 (630) \\
\hline - & $1992(1)$ & $1992(21)$ & 1992 (510) \\
\hline - & - & $1991(7)$ & 1991 (487) \\
\hline - & - & 1990 (17) & $1990(506)$ \\
\hline
\end{tabular}

${ }^{1}$ Analysis was conducted on 2019. ${ }^{2}$ There were publications of WP research in 1988 (2) and 1989 (2). ${ }^{3}$ Volunteering studies were published in 1987 (1), 1988 (4) and 1989 (27).

During the analysis of title-based searches in the WoS database, the largest quantity of emotional intelligence studies was encountered in the field of computer science artificial intelligence (34.091\%). However, the research we conducted should be categorized as belonging to the scientific field of management, which constitutes, as of now, 3.788\% of published EI studies. After performing the same function with the other phenomenon we are analysing, it was determined that the greatest number of intercultural competence research was published in the field of educational research $(40.212 \%)$, while the percentage of IC studies in the field of management was $5.820 \%$. Work productivity was abundantly examined in several fields, i.e., the fields of rheumatology $(16.565 \%)$, economics $(16.429 \%)$, health care services $(14.121 \%)$, health policy $(13.917 \%)$, etc. Within the field of management, work productivity studies constitute $5.227 \%$. Finally, the analysis of a number of volunteering research revealed its abundance in such fields as pharmacology pharmacy $(25.759 \%)$, neurosciences $(6.635 \%)$, psychiatry $(6.345 \%)$, management $(1.042 \%)$, etc. The performed analysis of the changes in the number of studies provides a conditional justification for the demand for this study, as the volunteer-receiving organisations first must deal with the issues related to management and working with human resources.

Table 2 presents a chronological order (by year of publication) of the definitions of the analysed phenomena; namely the concepts of emotional intelligence, intercultural competence and work productivity, which hold significance for the introduction of the empirical research results, presented afterwards. 
Table 2. The definitions of emotional intelligence, intercultural competence and work productivity.

\begin{tabular}{|c|c|c|c|}
\hline & Definitions & Authors & Year \\
\hline \multirow{6}{*}{$\begin{array}{l}\text { Emotional } \\
\text { intelligence }\end{array}$} & $\begin{array}{l}\text { The ability to recognise and understand one's own and others' emotions and to adequately express and } \\
\text { manage them. }\end{array}$ & Mayer, Salovey [10] & 1997 \\
\hline & $\begin{array}{l}\text { The ability to observe one's own and others' feelings and emotions, manage them, and utilise the accumulated } \\
\text { information in order to control thoughts and actions. }\end{array}$ & Brackett et al. [11] & 2011 \\
\hline & $\begin{array}{l}\text { Being able to understand non-verbal language, to perceive and express emotions, and to understand and } \\
\text { manage them. }\end{array}$ & Koubova, Buchko [12] & 2013 \\
\hline & $\begin{array}{l}\text { Emotional intelligence encompasses adaptation, internal and interpersonal skills, stress management and } \\
\text { general mood/health. }\end{array}$ & El-Chaarani [13] & 2016 \\
\hline & Emotional intelligence reflects the capability to establish and show empathy for others. & Bettis-Outland, Guillory [14] & 2018 \\
\hline & $\begin{array}{l}\text { Emotional intelligence is defined as the perception of one's self and one's moods, which also reflects the ability to } \\
\text { recognize, teach, gain experience, understand and utilize emotions. }\end{array}$ & Bacon et al. [15] & 2018 \\
\hline \multirow{7}{*}{$\begin{array}{l}\text { Intercultural } \\
\text { competence }\end{array}$} & An individual's ability to function efficiently in a different culture. & Gertsen [16] & 1990 \\
\hline & The ability to interact and communicate with representatives of different cultures. & Byram [17] & 1997 \\
\hline & $\begin{array}{l}\text { Cultural literacy, which allows one to read the signals and symbols of our own cultures as well as recognize those } \\
\text { that come from other cultural traditions. }\end{array}$ & Wilenius [18] & 2006 \\
\hline & $\begin{array}{l}\text { A collection of skills which enables one to work effectively in diverse racial/ethnic or } \\
\text { cultural/linguistic environments. }\end{array}$ & Rice [19] & 2007 \\
\hline & $\begin{array}{l}\text { It allows the group members to communicate with each other about their differences more effectively, i.e., to } \\
\text { evaluate how their actions affect group processes and to react more truthfully to the differences in another group } \\
\text { member's views or behaviour. }\end{array}$ & Lloyd, Hartel [20] & 2010 \\
\hline & It is knowledge about culture, skills and sensitivity. & Cai [21] & 2016 \\
\hline & The ability which increases one's capabilities of effectively communicating with representatives of other cultures. & Jyoti, Kour [22] & 2017 \\
\hline \multirow{5}{*}{$\begin{array}{l}\text { Work } \\
\text { productivity }\end{array}$} & An individual's ability to successfully complete tasks using the resources available in the workplace. & Jamal [23] & 2007 \\
\hline & $\begin{array}{l}\text { Productivity includes all factors that are significant in the pursuit of goals and can be measured separately } \\
\text { per each individual. }\end{array}$ & Randhawa [24] & 2007 \\
\hline & $\begin{array}{l}\text { Work productivity is the factor which encourages employees to work productively, implementing the } \\
\text { organization's strategy. }\end{array}$ & Kallio, K., Kallio, T. [25] & 2014 \\
\hline & Work efficiency draws attention to the team's behaviour and actions that could increase work productivity. & Fleury et al. [26] & 2017 \\
\hline & Shifting actions, behaviours and results that the employee achieves while working for the good of the organization. & Sujatha, Krishnaveni [27] & 2018 \\
\hline
\end{tabular}


Three main points emerge in the dimension of emotional intelligence: the ability to recognize one's own and others' emotions and to adequately interpret them; the stress-management skill, which emerges from understanding; the ability to adequately show emotions through communication. Emotional intelligence can be defined as empathy, which, aside from the necessary knowledge, is needed in order to establish a productive dialogue. Emotional intelligence can ensure sensitivity towards people from other cultures, but, apart from the cultural knowledge of the volunteering location, practical skills are required for application of the abilities. Work productivity criteria include requirements such as the ability to blend into a team and complete tasks by cooperating. Nonetheless, research demonstrates a one-dimensional perspective, in which requirements are imposed on the volunteers, while the capability of the volunteer-receiving organization itself to integrate them is underestimated.

In order to provide a theoretical justification for links between emotional intelligence, intercultural competence and work productivity, an overview of scientific studies on the analysed subjects is presented below.

A large number of authors explore the relations between emotional intelligence and work productivity $[12,13,28,29]$. It is claimed that some organization employees can work more productively as a result of higher emotional intelligence [29,30]. Koubova and Buchko [12] underline that regardless of the role we assume (an employee, family member, friends), emotions have an impact on our feelings and state of mind, which affects our ability to work and fulfil the job requirements properly. Emotions also have an effect on people's concentration and continuity of tasks at work. On the other hand, it has been observed that certain events (illnesses, separations) in some cases may have a much stronger and longer effect, which makes people unhappy and decreases work productivity and general satisfaction with life [12,31]. Because of this, it could be claimed that work productivity, i.e., specific results, often depends on the individual's ability to deal with both positive and negative emotions that have an impact on his/her psychological condition. It is significant that emotional intelligence starts developing in childhood, when one is communicating with family and friends [10,32], which is why a person who starts working should already have developed the social and emotional competences that are required in the job. The results of studies conducted by the previously mentioned authors confirm that the higher emotional intelligence, the easier it is for this person to separate the borders between work and personal life and to react to disturbances, which in turn leads to higher productivity at work.

Investigating the impact of emotional intelligence on work productivity, Tischler et al. [30] noted the influence of separate components of emotional intelligence on work productivity. For instance, self-confidence had a significant impact on this. Furthermore, people who are able to manage themselves and work honestly achieve better work results. When providing various services to other people, in order to achieve better results, particular significance is placed on the service provider's social competences, while dedication and awareness with regard to the organization should improve the employees' work productivity. Thus, not coincidentally, when searching for new employees, the highest demand is for better social, leadership, communication, conflict-solving and teamwork skills.

Other studies show (e.g., by Wong and Law [33]) that emotional intelligence is directly related to work satisfaction and work productivity. People who have high emotional intelligence are more self-confident and feel in control of the work environment, which enables them to stabilize and perform the assigned tasks better. Moreover, individuals who have high emotional intelligence cope with work-related stress easier and are able to manage their emotions. Moreover, as noted by Cote and Miners [29], when work productivity is low, it can be increased using emotional intelligence. In this case, it is important that the employee is able to recognize and understand not only their own, but also others' emotions that are expressed verbally, through body language, or facial expressions. Those whose emotional intelligence is high are able to recognize the signals that are sent and provide information about the person, which is why such a colleague can become a helping hand to other employees by identifying sadness or anger and helping others to recognize those emotions [34,35]. In addition to this, emotional intelligence helps increase work productivity depending on how the management of emotions affects social relationships. Employees who display an honest concern for others and 
do not hide their true emotions tend to establish stronger relationships with their colleagues. Such relationships increase the likelihood of receiving more advice that is useful and honest; moreover, they can provide social support to one another, which ensures higher quality of the performed tasks $[29,33]$. On the other hand, empathy can be equated with virtue, which is the "golden mean" between two extremes. In other words, both insensitivity and excessive empathy may result in non-achievement of the desired outcome, because in one case, the connection is lost, and in the other case, the focus is solely on emotional experiences. Finally, emotional intelligence increases work productivity, depending on what people are thinking and how they conduct themselves. The employee who can control their emotions in such a way that they would increase motivation and allow them to make the appropriate decisions will be much more productive. For instance, if the manager understands that anger makes one overestimate the threat of the risk, they will use the methods acceptable to them in order to suppress the anger before making a decision, which brings about significantly better results $[29,36,37]$. Thus, it is difficult to overestimate the impact of emotional intelligence on a positive psychological state and quality of social relationships. For example, Devonish [38] observes that a good psychological state is strongly related to emotional intelligence and work performance. The author claims that a healthy psychosocial environment at work is one of the fundamental aspects that help employees to increase work productivity. He also singles out the importance of training related to emotional intelligence as one of the methods of intervention for the purpose of achieving better work results. Development of the employees' emotional intelligence could create additional value for the employee themself, thus raising their motivation to work and simultaneously reducing the risk of disturbances of mental health. Other authors [39] emphasize the significance and impact of emotional intelligence in the context of social service provision. Due to its specificity, such work is often considered to be emotionally intense [40]. People who work in this field must be capable of sensing, understanding and recognizing not only their own but also others' emotional states, and utilise their emotional skills to adequately perform the task they have been assigned. In another study, Guy and Lee [39] examined how emotional intelligence changes while conducting tasks and how it influences the quality of the performed tasks. One of the key results of the research was that the ability to regulate one's emotions decreased the risk of professional burnout, which is frequently encountered in the sector of social services.

In short, it could be claimed that the evidence that was provided by various authors and which has significance to the context of our study has confirmed that emotional intelligence has a strong impact on more than just work productivity. The ability to recognize and control one's emotions is one of the fundamental competences and personal characteristics that should be developed and is required for the adequate performance of the assigned tasks, the support of a healthy psychological state, and productive social relationships with co-workers and other interested parties. This is important for volunteers who work in the field of social work in other cultures and face various unconventional situations. For this reason, below we will review several studies that evaluate the relationships between intercultural competence and work productivity and also emphasise the significance of emotional intelligence in the development of intercultural competences.

During the course of human history, there have been a variety of expansions into culturally divergent countries; however, recent decades have seen a rise in the studies and discussions on intercultural competence due to the intensified globalization processes. Globalization has a strong impact on all organizations and lack of understanding cultural differences is one of the key challenges [41]. To successfully deal with the pressure caused by globalization and differing work conditions, organisations require a manager who is sensitive towards different cultures. Managers should focus on the differences, because a culturally diverse workforce is more productive and capable of proposing a greater amount of new ideas from their own culture [22]. Furthermore, previous research has shown that intercultural competence has a strong impact on intercultural adaptation and work productivity [22,42-45]. It is one of the fundamental competences of the 21st century. While exploring this issue, Jyoti and Kour [22] claim that emigrants who have a developed intercultural intelligence can effectively and easily communicate with people from other cultures and initiate social integration, which improves their work performance; 
additionally, it allows them to decrease uncertainty and anxiety that can often emerge in a foreign cultural environment. On the other hand, people who find it difficult to adapt abroad are often incapable of performing the tasks they have been assigned, which can add additional expenses for the organization or even harm its reputation and relations with the accepting country, thus losing the opportunity of working in the area [22].

Work productivity consists of knowledge, skills, abilities and motivation oriented towards the conduct ascribed to one by the assumed position [46]. Moreover, Jyoti and Kour [47] claim that work productivity and intercultural competence are closely inter-related. People who come from another culture often achieve lower results in the work context, struggle more with perceiving the existent cultural differences and find it hard to get accustomed to their new role. Meanwhile, according to Ang et al. [48], individuals who take more care of the environment and tend to adapt depending on the situation are much more perceptive and accepting the culturally appropriate role both in the society and the workplace. Openness to other cultures decreases barriers, because, according to Kumar et al. [45], people who are able to adapt to different intercultural situations are more likely to perform the assigned tasks more easily. Adaptation in an intercultural environment is precisely one of the deciding factors of the foreigner's success in the workplace. This ability reduces stress and tension, which increases work productivity and quality [47]. It is probable that the individuals who can adapt to the general environment of the accepting culture are able to work with similar productivity as in their home country.

Modern literature singles out intercultural team management as an important aspect of human resource management [49]. Culturally educated managers are aware of the values, faiths, behaviour models, traditions, customs and languages of different cultures. This allows them to react appropriately to different situations [42]. However, work in a multicultural team is often very complex. In spite of the likelihood of conflicts arising because of underdeveloped intercultural competence [50-52], it is highly important to understand the essential aspects of working in such teams. After all, it is worth discussing what is required for successful and effective management of the intercultural team. Dusi et al. [53] claim that the key skills are self-knowledge, social skills, cultural awareness and organizational knowledge about the workplace. That is, first, one has to understand one's own emotional responses while working with other people, to recognize the impact of arising problems or emotions. Second, it is important to know how to establish a contact with another person, how to create trust between the service provider and the recipient, sometimes in a very short period of time; these things are key to achieving a good relationship with another person. Third, one of the tasks of the person working with different cultures is to create open communication between two completely different cultural worlds in such a manner that they could interact and trust one another. Fourth, one needs knowledge about the organization where one is working, because each organization has its own "micro-universe" with its own rules, customs, language etc. Still, even while following the knowledge and skills of this field, many misunderstandings may arise and sometimes evolve into serious conflicts; therefore, in order to ensure the intercultural team's productivity, its leader has to be capable of dealing with the arising conflicts professionally [20,53-55]. Continuing the analysis of this issue, in a recent study, Kenesei and Stier [54] argued that cultural differences also have a high impact on relations between representatives of different cultures, especially if the cultures are distant from one another, and thus, the existing expectations may not match the reality. This study echoes the observation by Terry [56] that because of this, it is important to organize employee training during which they could get better acquainted with different cultures and develop their intercultural competence, allowing them to work productively later both individually and in teams. Other research has shown that intercultural competence is closely related to emotional intelligence; we will briefly discuss the studies of the latter.

The prevalent trends in the world have resulted in many organizations of today facing the context of unknown cultures and a culturally diverse workforce, which causes a number of previously unencountered issues that are not always solved with adequate responses and productive management solutions. Moon [57] underlines that this confrontation of intercultural perspectives could cause many 
challenges for people and the organizations themselves because cultural differences can frequently raise tensions of various kinds [57], the more so since problems arise not from the cultural context in the broad sense, but bearing in mind contrasting values and diverging perspectives on certain issues. This is because the ability to effectively communicate with individuals from different cultures is increasingly needed in order to be able to solve problems that arise due to the intercultural context. In this context, it is important to note several differences in cultural and emotional intelligence as observed by a number of authors. Intercultural competence reflects the ability to collect knowledge, interpret and behave adequately and effectively depending on social hints, while emotional intelligence does not encounter this directly [57]. Emotional intelligence encompasses the individual's capability to accept, perceive, manage and react to culturally similar persons. Furthermore, cultural intelligence is also different due to its focus on intercultural interactions, which is absent from the concept of emotional intelligence; for instance, the knowledge of how to shake the hand of another culture's representative does not necessarily involve emotional intelligence [58]. Despite the differences, both concepts are united by openness and sensitivity towards others. Because of this, even though Clark and Polesello [59] do not state this directly, they do argue that to create a well-rounded organization, where cultural diversity would give the greatest possible benefit, emotional intelligence and intercultural competences are among the essential factors that determine the realization of such organizations. A diverse workforce can cause both positive and negative results, as well as emotions in response to certain events. Positive results of a diverse workforce are often specified to be creativity, innovation and competitive advantage [60]. Conversely, negative results are tension and conflicts that reduce productivity and efficiency [61]. According to Clark and Polesello [59], when people talk about cultural diversity, the conversation often provokes rather difficult and complex dialogues that cause a multitude of emotions. When pondering the relationships between culturally diverse workforce and emotional intelligence, it can be argued that the individual who is capable of recognizing and managing their emotions can increase the perception of interactions in the intercultural environment.

Antonakis et al. [62] also use the concept of emotional intelligence in their argument that emotionally intelligent workers can effectively manage different concepts and evaluate their individual differences. Those who have a well-developed emotional intelligence are usually in good spirits, which provides an opportunity to process information better, distribute it and use it creatively. Furthermore, leaders who have high emotional intelligence are recommended to enable and promote employee creativity with five methods: identification, information collection, idea generation, idea modification and idea implementation [63]. Remembering that one of the results of intercultural competence is creativity $[59,64]$, it can be claimed that it is yet another connection to emotional intelligence.

As stated by Lilis and Tian [65], in a culturally diverse context, emotional intelligence effectively complements intercultural awareness and provides the opportunity to achieve the highest possible productivity with the help of empathy and social skills. Thanks to increased sensitivity to and awareness of cultural diversity groups, the obstacles to intercultural communication are reduced to a minimum, thus raising the likelihood of success in the market. Display of culture-related emotions is a kind of work, which requires effort, planning, participation and adaptation to the situation [66]. Because of this, Tan et al. [66] introduce the model of culture-emotion interaction, which defines the interactions between cultural orientation and emotions. This model provides information that enables one to lend a helping hand to a human resource specialist in the search and selection of employees from different cultural groups based on the candidate's level of meeting the employee requirements and overall cultural personality. Furthermore, this model draws attention to the fact that knowledge of the accepting culture, communication skills, emotion management and emotional intelligence as a whole are some of the key factors for achieving the best results.

Thus, the overview of scientific research shows the existence of links between all three objects: emotional intelligence, intercultural competence and work productivity. Emotional intelligence complements intercultural competence, reinforcing the ability to recognize emotions related to cultural differences, whereas the ability to recognize and manage one's own emotions significantly contributes 
to increasing work productivity. While working in an emotionally complex job in particular, which characterises volunteering in a different cultural environment, emotional intelligence helps one better understand what is going on both with the employee themself and the individuals with whom they are working. Studies also confirm the connection between work productivity and intercultural competence, which is especially significant for different societies, considering how, for example, globalization manifests itself in specific societies.

\section{Research Methodology}

Based on Braun and Clarke [67], qualitative research enables to observe the researched phenomenon from a multifaceted and complex perspective and to discover things that are typically impossible to measure or grasp. The method of semi-structured interviews was used in the collection of data for this study (Table 3).

The interviews were carried out employing prepared research guidelines: constructed broader questions that were based on scientific literature related to emotional intelligence, intercultural competence and work productivity in a general sense and to the analysis of these phenomena in volunteering as a guide.

Research participants were chosen using targeted selection. During the study, it was important to acquire significant, practice-based information; therefore, research participants had to have at least one year of experience in volunteering. In order to collect as detailed data as possible, the persons taking part in the study had to have worked directly with foreign volunteers: as mentors, tutors, project coordinators and sending coordinators of the European Voluntary Service (EVS). In order to ensure objectivity of the study results, interviews were conducted with two different persons fulfilling the aforementioned roles (three project coordinators took part in the research). In total, the study involved seven informants selected with the help of the local EVS project-coordinating organisation, where the contacts of some of the participants were obtained. Other participants were found using snowball sampling: they were recommended by the already participating research informants.

The principles of research utility and fairness were upheld during the study. Research participants were verbally guaranteed their privacy (informants were protected from responding to questions they found unacceptable and their decision was honoured), confidentiality (informants were informed that the data received in the interviews will only be preserved in the written form, i.e., only as the transcribed text, while the digital recording of the interviews will be destroyed) and anonymity (informants were informed that information about them will be presented in a depersonalised form, using codes). Research participants were treated respectfully and fairly.

This study used qualitative content analysis, which made it possible to systematically describe the available qualitative data, i.e., by arranging the data into consistent categories that are coded later. Such analysis reduces the amount of data, as it is systematized and flexible. Qualitative content analysis consists of the following stages: raising the research question, data collection, coding, segmentation, test coding, evaluation and code modification, principal analysis, presentation and interpretation of results [68]. After raising the research question (the first stage), conducting interviews (the second stage) and transcribing the text (the third stage), the qualitative analysis of the obtained data was performed, i.e., the received responses of informants were subdivided into subcategories (the fourth stage) and the latter were categorized (the fifth stage). The sixth stage consisted of conducting presentation and interpretation of results.

While conducting the qualitative study, seven individuals who work directly with foreign volunteers in Lithuania were interviewed. Conversations were held with mentors, tutors, sending coordinators (SC) and receiving coordinators (RC). All of them have over two years' work experience with volunteers, one of them no less than 19 years. The organisations that they work with also have a lot of experience working with volunteers. More detailed information is provided in Table 4, where codes are assigned to each informant. 
Table 3. Interview outline.

\begin{tabular}{|c|c|c|}
\hline Categories & Sub-Categories & Samples of Primary/Main Interview Questions \\
\hline \multirow{2}{*}{$\begin{array}{l}\text { Structures of work with } \\
\text { foreign volunteers }\end{array}$} & Volunteering model & \multirow{2}{*}{$\begin{array}{l}\text { As a mentor/tutor/coordinator, how many years in total have you been working } \\
\text { with ... ? When was the mentor model introduced in your organisation? Have you } \\
\text { counted how many volunteers you have had or accompanied? In your opinion, } \\
\text { which field is the most popular, i.e., which field usually receives the largest number } \\
\text { of volunteers? Speaking of the social field, could you specify if it is youth, children, } \\
\text { or the disabled? }\end{array}$} \\
\hline & Volunteering field & \\
\hline
\end{tabular}

Ability to recognize one's own and others' emotions

Emotional intelligence

Ability to communicate with others
What influence does the volunteer's ability to recognize and understand other people and their body language have on his/her work? How does the fact that a volunteer is able to control his/her emotions contribute to the development of his/her well-being or inclusion/work in the organisation? The ability to communicate with others-how much does it help one to get involved in the organisation's activities or the local community? Why is it important for a volunteer to be able to recognize his/her emotions?
Adaptation

Beliefs

Intercultural competence

Personal characteristics of volunteer
What could improve adaptation in a new place/culture while working in an organisation? What influence does a volunteer's intercultural perspective/beliefs have on his/her ability to, first of all, accept and get involved in communities of another culture or establish relations with people from other cultures? What characteristics should an interculturally conscious volunteer have? What makes a volunteer considerate in an intercultural context (which characteristics, views, traits)? During the volunteer selection process or while working with a volunteer, what signs do you look for to determine whether he takes foreign cultural factors (e.g., religion, race, language) into consideration? What does a volunteer gain from the possessed/acquired intercultural knowledge? What would help a volunteer get involved more easily in the life of a new culture/become a part of its society?

Knowledge

Which characteristics/traits allow one to assume that the incoming volunteer will be productive? How can a volunteer be encouraged or motivated in the workplace?

Work productivity

Volunteer productivity

Volunteer motivation 
Table 4. Informant characteristics.

\begin{tabular}{|c|c|c|c|c|c|c|c|}
\hline Characteristics Code & I1-M & I2-T & I3-T & I4-SC & I5-RC & I6-RC & I7-MSC \\
\hline Assumed position & Mentor & Tutor & Tutor & Sending coordinator & $\begin{array}{l}\text { Receiving } \\
\text { coordinator }\end{array}$ & $\begin{array}{l}\text { Receiving } \\
\text { coordinator }\end{array}$ & $\begin{array}{l}\text { Mentor, sending } \\
\text { coordinator }\end{array}$ \\
\hline Time in office & 5 years & 19 years & 2 years & 3 years & 4 years & 3 years & $\begin{array}{c}\text { Mentor- } 4 \text { years, } \\
\text { coordinator }-5 \text { years }\end{array}$ \\
\hline $\begin{array}{l}\text { Duration of the organisation's } \\
\text { functioning/existence }\end{array}$ & 15 years & 19 years & 3 years & 17 years & 3 years & 3 years & 15 years \\
\hline Informant's education & Social work & Pedagogy & Public relations & Art history and criticism & Political sciences & Politics & Arts \\
\hline Informant's age & 32 years & 46 years & 29 years & 27 years & 26 years & 30 years & 32 years \\
\hline $\begin{array}{l}\text { Personal experience as participant in } \\
\text { the European Voluntary Service } \\
\text { (EVS) project }\end{array}$ & $\begin{array}{l}\text { Working with } \\
\text { youth, Germany }\end{array}$ & None & None & $\begin{array}{l}\text { Working with the } \\
\text { disabled, Italy }\end{array}$ & None & $\begin{array}{l}\text { Working with } \\
\text { youth, } \\
\text { Netherlands }\end{array}$ & $\begin{array}{l}\text { Working with children } \\
\text { and the elderly, } \\
\text { Lithuania }\end{array}$ \\
\hline
\end{tabular}




\section{Results}

Work with the volunteer is primarily dependent on the inter-relations among involved organisations (receiving, coordinating, sending) and established work systems. One of the examples ensuring smooth cooperation is, according to I5-RC, personal relationship with the organisations: "...our organisations have been selected very personally so far, where there's a personal connection with the employees...". This helps, because both sides then have a sense of personal responsibility and they already trust one another, whereas if there is no close connection, “... you have to create some sort of a system...". I1-M emphasises the importance of mentors' individual approach to volunteers: "...as mentors, we take each of them as a phenomenon. I don't compare them as a whole, I work with each of them, so that they would receive each person like this as well...". I1-M and I5-RC talk about the most effective type of volunteer-organisation support system. This system should include at least four people. I5-RC claims that "...the coordinator manages practical matters, the tutor [works] on site, so the mentor is completely external and that local friend involves [him/her] in the activities that are not related to the work, like going somewhere or eating out or a basketball game...". Nevertheless, aside from the classical structure used by receiving organisations, at least six sub-categories in the structure of work with foreign volunteers can be distinguished. These are presented in Table 5 .

Table 5. Structure of work with volunteers.

\begin{tabular}{|c|c|}
\hline Sub-Categories & Statements \\
\hline Volunteer's adaptation & $\begin{array}{l}\text { I3-T: "As we say, they stay here a month, find their feet, get in contact, observe the } \\
\text { situations, we talk. Later we give them the freedom to act, I don't say 'Go draw with } \\
\text { the kids' if you're not good at drawing. We look what suits best. It all [depends] } \\
\text { on the volunteer". }\end{array}$ \\
\hline Volunteer's return & $\begin{array}{l}\text { I7-MSC: “... coming home is, again, a culture shock of sorts, where you've changed so } \\
\text { much, and you return where nothing's changed. So, it requires determination as well. } \\
\ldots \text { To [accept] that these changes happened only to you... And you are alone and you } \\
\text { can't express everything that you have experienced..." }\end{array}$ \\
\hline $\begin{array}{l}\text { Personal relationship } \\
\text { with organisations }\end{array}$ & $\begin{array}{l}\text { I1-M: "It works best then, because you achieve the result through } \\
\text { personal relationship..." }\end{array}$ \\
\hline $\begin{array}{l}\text { Personal experience of the } \\
\text { person preparing volunteers }\end{array}$ & $\begin{array}{l}\text { I5-RC: "If the person who is preparing hasn't been there, preparation is only theoretical. } \\
\text { And it is hardly effective at all ..." }\end{array}$ \\
\hline $\begin{array}{l}\text { Experience of the } \\
\text { organisation which } \\
\text { sends volunteers }\end{array}$ & $\begin{array}{l}\text { I2-T: "It's best when you have a long ... long period of cooperation with certain } \\
\text { organisations that are reliable, know the projects, where it's not the first time already..." }\end{array}$ \\
\hline Openness to the volunteer & $\begin{array}{l}\text { I1-M: "There have also been some projects where the volunteer ... is a professional and } \\
\ldots \text { really sees the right direction to move towards, but the project, because of the } \\
\text { internal turmoil, cannot hear this and cooperate..." }\end{array}$ \\
\hline
\end{tabular}

Still, the volunteer's preparation for volunteering begins even before departure for a specific country and project. One of the key roles here is played by the sending organisation, which is responsible for the volunteer's thorough preparation for volunteering. Sometimes the organisation that is sending the volunteer finds it difficult to prepare them properly for a different, intercultural environment if, in the words of I5-RC, the preparing person does not have personal experience in the country to which the volunteer is being sent. However, according to I5-RC, even such a theoretical preparation can help the volunteer adapt better in the new environment, because, as I7-MSC claims, "...it is very difficult to prepare [someone] for practical experience...". Regardless, I3-T underlines that “...if [the volunteer] hasn't had any experience, then he should definitely put in more effort into preparation...". Speaking about the volunteer's thorough preparation, I4-SC states that, before departure, the preparation itself "...is usually split into two parts. ... So the first part has information, questions-answers about it [the project] from scratch, what is EVS, how many hours they volunteer, how many vacation [days] they have, what's covered by insurance, what isn't, checking out, checking in, various numbers, everything is in the info package, this practical information. ... And what's key in 
the second part is individually set goals, what he wants to achieve by volunteering...". SOs also often help the receiving organisations to select volunteers. I2-T emphasises that it is best when the SO has many years of experience so that they "...can conduct a very targeted selection...". I4-SC claims that in order to select the most suitable volunteer, he "...can be provoked on various issues, I don't do that inquisitional selection. But there are seasoned organisations that have prepared questions about it...".

The receiving organisation emphasizes openness to the volunteer, enabling it to grow and improve. This is confirmed by I1-M: “...the volunteer can be a great help for the organisation's growth, and there have been many experiences where communication was good and the projects acknowledge that wow, you helped us a lot, you gave us a direction...". The competences of each employee, the ability to establish a trust-based relationship with the volunteer are also significant: "...[sending] the message [to the volunteer] that you are important, saying where the added value is, providing feedback. Even if the employees are unable to say a lot the volunteer is like a cannonball...". I2-T, I3-T and I7-MSC highlight the importance of the volunteer's adaptation in a new location. For instance, I7-MSC emphasises that, at the start of volunteering, it is important that the volunteer is familiarized with "... both the target group and the team. In the beginning getting familiar is very important...". In addition, I2-T claims that it is necessary to establish a relationship with the volunteer, to learn from one another: "... what helps is that we have a kind of discussion and reflection monthly...". I6-RC thinks that volunteers can give additional support, but their abilities must be taken into account and tasks given must be suitable to their skills: “...what matters most is that you don't try to use the coming volunteer to plug up a part you want but to find a place that suits him/her in your organisation. If he/she can't work with children, then he/she can't, and you don't give him/her that...".

The final stage of volunteering is usually followed by various self-assessments that are held both at the receiving organisation and after returning to one's home country. I4-SC states that he has ".... system of how I follow them; when they finish their projects, I offer them to meet, also there's an annual follow-up seminar organised by the Lithuanian National Agency, which also includes self-assessment, but all contact must not be forced...".

The volunteer who has low emotional intelligence often faces certain difficulties. One of them is the inability to recognize one's own and others' emotions. According to I3-T, this inability turns into a problem at the workplace: “...It was a girl with problems, she didn't admit it to herself, and we didn't understand at first, she found everything very much out of place here..." I2-T and I5-RC note that the significance of emotional intelligence, particularly while working with vulnerable social groups, is very high: "...one volunteer did not have this ability at all, she had certain disorders that limited the ability to understand another person, so work was simply impossible. She didn't understand children, colleagues, and due to this other volunteers suffered too...". I6-RC expanded on this: "...when you work with children, it is also important to read children, to find common ground with them, to know when to approach, to ask right questions or to react somehow to their feelings...". I7-MSC claims that the ability to perceive other people's emotions and to recognize them helps one to better "...adapt perhaps and accept differences or different situations...". The response by I5-RC also demonstrates the importance of recognizing, managing, and understanding one's own emotions: “...Yes, it's important for them to understand their emotions, because only then they are able to make full use of all possibilities...". The development of the ability to recognize and understand one's own emotions, according to I4-SC, can be enabled by the environment: “...understanding of one's emotional state can be aided by the environment, the people around you with whom you feel comfortable, who listen; when you talk to them, you don't need to think how you look, how you sound; whom you trust...". Furthermore, accompanying the volunteer, reflecting together with them is also important. On the other hand, the informants also underlined the role of the mentor's emotional intelligence while aiding the volunteer to recognize his/her own emotions. For instance, I5-RC claims that help is often provided to the volunteer in order to enable them to understand what they are feeling at any given time: "...And when he/she says that, he/she opens himself/herself up for that change. And that change goes straight to the organisation because then, through positivity, understanding of his/her emotions, he/she can change and manage 
them...". Moreover, "... If the volunteers do not understand their emotions, they experience turmoil and depression. They are incapable of using that time to change and improve themselves...".

Speaking about another component of emotional intelligence-social skills-the research participants specify self-reflection as one of the key elements. I1-M claims that the abilities "...to recognize your own responsibility, the ability to thematize feelings, the ability to discuss unpleasant subjects ..." ", "...the ability to share how you feel in general, ... to endure hardship..." facilitate involvement in the organisation's life and activities. It encourages volunteer integration, helps to establish relationships and interaction with the organisation's members. I2-T notes that "...if [volunteers] come unprepared, they fall into the sea, so to speak, with no tools, no preparation, they imagine that the sea is the beach, but the sea is not the beach, there are storms, there are all kinds of things...", it becomes much more difficult for them to reflect on their experiences and feelings. I1-M's answers make it clear that, while trying to help the volunteer, it is crucial for the mentor to give him enough space and progress together with him, without pushing him too much: "...it requires time and a relationship, and sometimes it happens; it really seems that the conversation is a bit burned up, not too sensitive, then, I try to wait calmly for the next time, and sometimes things really change, they settle down...". Speaking of social skills, I7-MSC, I5-RC and I1-M highlight curiosity, desire to get to know others, proactiveness, critical thinking and motivation. For instance, I3-T observes that "...the more you nurture universal human things in him, the more motivated the person becomes, then he starts to get very interested or, on the contrary, not interested...". I4-SC argues that the desire to learn is also important: "...EVS projects ... are namely about informal learning experiences, not about gaining some skills but about emotional growth, how he/she perceives himself/herself...". I5-RC emphasises the volunteer's activeness, curiosity, courage to overcome language barriers and the ability to develop relationships with other people.

The responses show the impact of emotional intelligence on relationships with other people and the organisation's clients. I1-M says that "...it is a breakthrough moment in integration when they have a relationship with a Lithuanian...". I2-T underlines that in relationships, only "...a healthy person..." is able to effectively interact with others and share experiences with the target group. I3-T claims that, for instance, volunteering with children can be taken on only by "...emotionally strong and stable people. To see when and where help is needed...", "... to be able to recognize your own emotions, because you are surrounded by children, who will definitely not control their emotions...". Answers of I6-RC revealed that internal support influenced the ability to develop relations with other people: "... it gives a good feeling for such volunteers, among them, if it is a larger group...". The responses also reveal the importance of the level of the relationship between the volunteer and the organisation. For example, according to I6-RC, “... the organisation's emotional preparation is also very important for quality work. So, the employees themselves have to be emotionally prepared and open too...". If the employees themselves are unprepared to reflect on their experiences, then it becomes very difficult to accompany the volunteer and to expect them to be open to the organisation and to retain motivation to work.

Summarizing informants' responses, the main sub-categories can be distinguished, testifying not only to the success of the mission undertaken by the working and cooperating volunteer, but also to the state of the volunteer themself. The details are provided in Table 6.

Table 6. Emotional intelligence.

\begin{tabular}{ll}
\hline \multicolumn{1}{c}{ Sub-Categories } & \multicolumn{1}{c}{ Statements } \\
\hline Volunteer's emotional intelligence & $\begin{array}{l}\text { I7-MSC: “...if you don't understand your own emotions, then it's very } \\
\text { difficult to understand others as well. So this is the key [ability]...” }\end{array}$ \\
\hline Skills & $\begin{array}{l}\text { I2-T: “...it requires basic social skills that are needed in daily life and } \\
\text { everything else...” }\end{array}$ \\
\hline Motivation & I2-T: “...if you choose [volunteering], you have very clear motivation...” \\
\hline Mentor's emotional intelligence & $\begin{array}{l}\text { I6-RC: “...you have to become a mirror }<\ldots . . \text { > to say: well, I see that } \\
\text { you're angry now, why are you angry?” }\end{array}$ \\
\hline
\end{tabular}


Thus, not only the volunteer's but also his/her mentor's emotional intelligence level is important. It is also essential that the volunteer is open and willing to understand and identify what is happening with him/her, and is provided with the possibilities to develop his/her emotional intelligence at the receiving organisation.

While volunteering abroad, intercultural competence becomes important both in the development of relationships with surrounding people and working in organisations. The informants' responses enable to distinguish the characteristics that help to adapt easier in the new environment, one of them being the volunteer's openness. I7-MSC says that "...openness, leaving your prejudices at home and arriving with an open heart, not following stereotypes, ..." makes it easier to approach people. I1-M and I4-SC distinguish curiosity and high activeness as also helping people to get acclimatized in another culture. E.g., I4-SC stresses that “...an active person doesn't necessarily have to be brave, because you gain courage in the environment; but to get familiar with the environment, you have to go, look, not give up. If you didn't like one person, it doesn't mean that you won't like all. There should be a desire to go and get to know things...". I6-RC and I3-T emphasize that it is also important to understand the historical side of the country why people conduct themselves one way or another. Knowledge of the country's culture is another factor enabling to get immersed in the new environment and providing the sense of security. In the opinion of I4-SC, "...if you feel safe in the country to which you are travelling, you are braver. There are moments of disinformation, when you think you know, you heard... prejudices can impede from the very beginning...". Even minimal knowledge about the country you are travelling to can have a dramatic impact on the experiences awaiting there. According to I6-RC, “... time spent together with the organisation informally, the organisation's openness to the volunteer, then the volunteer's willingness to go and interact, not being afraid to interact, talk, be, participate..." also help to get involved in the local community. I5-RC claims that "...all volunteers have the language barrier, don't speak Lithuanian, sometimes organisations have problems with the English language..."; therefore, it is important to understand that one does not have to feel shame and fear because they are not the only ones.

I1-M observes that a lot of support can come from the locals, who can share their experiences and explain certain behaviours. I6-RC says that, when you have "...a Lithuanian acquaintance, it's much easier.". I7-MSC underlines the community of other volunteers, although "...they do not integrate as much. But, as far as I've noticed, going [together with someone] [makes them] more confident. In larger cities, it is easier to discover cultural activities, to get involved in local structures...". In the opinion of I5-RC, the crucial period is "...during the first and second month, before they have found all those personal connections...". Still, not all volunteers are able to adapt to the new culture. I5-RC notes that the volunteer's "...high internal standards ... and the internal perception that he cannot influence all those cultural differences..." result in not fitting in the new environment. I6-RC also notices the influence of the group. If "...the person disassociates himself/herself from that group, he/she feels lonely...". I1-M highlights that namely after failing to integrate into the local community or organisation, "...homesickness sets in..." and more serious problems begin. I1-M, I2-T, I3-T, and I6-RC emphasize that, for this reason, it is important to have a support system which would allow the volunteer to reflect on their experiences, share their emotions and receive support and encouragement.

Summarizing the informants' responses, four sub-categories or factors significant to the volunteer's intercultural competence can be distinguished. They are presented in Table 7.

The informants' responses show that such factors as openness, knowledge of culture, beliefs, respect and tolerance of local cultural aspects, and the ability to establish friendships not only affect quality of activities, but also ensure better integration and personal well-being.

In the context of work productivity, I3-T singles out emotional intelligence as one of the crucial characteristics enabling to "...recognize your [emotions], later the co-workers' emotions, to whom also all kinds of things happen, also children's and the parents' emotions...". This ability can significantly contribute to the quality of performed tasks. Nevertheless, according to I7-MSC, the volunteer's productivity is affected by the very "... beginning, getting acquainted with both the target group and 
the team...", because it allows one to feel as part of the team, to understand that the team trusts the volunteer, and "...that is very motivating...". This is also the case with the volunteer's "...involvement in various activities, which motivates further, when the volunteers are trusted more and more, allowed to initiate their own activities...". I1-M underlines that "...if the project and the volunteer are in conflict, the project will not benefit from volunteers, and vice versa...", because mutual trust increases the added value. I7-MSC notes that when tensions arise in the team, the organisation does not understand "... why this demotivates the volunteer to be there so much...". For this reason, again, it becomes highly important to reflect on experiences, to discuss the problems preventing the volunteer from being effective in the workplace, because as long as they do not know "...what those tensions are all about, they are taken personally...". Another method of encouraging the volunteer to focus on the performed tasks is goal revision. Before departure, volunteers often set some goals for themselves to achieve. I4-SC underlines that, if "...actually primitive goals were set and there is nothing to learn, perhaps it's time to revise them. Perhaps there are other reasons they don't reveal why they don't want to perform the activities they signed up for...". Namely, goal revision and renewal enable the volunteer to complete the tasks he had started, ensuring their quality as well.

Table 7. Intercultural competence.

\begin{tabular}{cl}
\hline Sub-Categories & \multicolumn{1}{c}{ Statements } \\
\hline Openness & $\begin{array}{l}\text { I6-RC: “Openness ... is most needed for [the volunteer] not to block himself/herself and } \\
\text { not to say that it's all uninteresting, it's better where I am from...” }\end{array}$ \\
\hline Knowledge & $\begin{array}{l}\text { I6-RC: “...talking with one another, introduction, participation, familiarisation, a bit of } \\
\text { history, this comprehension...” }\end{array}$ \\
\hline $\begin{array}{c}\text { Beliefs and } \\
\text { respect }\end{array}$ & $\begin{array}{l}\text { I3-T: “....a wise, tolerant perspective on the traditions of a foreign country, respect for } \\
\text { values, respect for both universal human values and traditionally established values". }\end{array}$ \\
\hline $\begin{array}{c}\text { Relations, } \\
\text { friendship }\end{array}$ & $\begin{array}{l}\text { I1-M: “...coming into contact with this Lithuanian, ... is a very big breakthrough for } \\
\text { integration, they start to see Lithuania differently. I see that those volunteers who have } \\
\text { Lithuanian friends integrate completely differently, they do not need so much help”. }\end{array}$ \\
\hline
\end{tabular}

Discussing work productivity, I1-M and I2-T highlighted motivation as an important component of this construct. However, I2-T also says that "...sooner or later 'I feel useless'"'“...", speaking about the phase, when the volunteer does not see the point in performing the tasks. I1-M claims that "...the project has a life of its own, a process. And at first there's a lot of focus, you have a list of primary tasks, then they don't even make a second list, everyone goes back to their work, and you don't know what to do for that whole day...". I5-RC observes that "...this is learning of sorts during the first part, while in the second stage, it's that ability to take the initiative...", thus, the volunteer themself has to contribute so that the phase of uselessness occurs as rarely as possible. Naturally, the focus on tasks depends on how interesting they are. I5-RC notes the trend that "...while he is learning to perform it, his engagement is very high, it's new to him and he's trying to learn..."; however, once it becomes a routine, motivation decreases. I7-MSC emphasises that, in such cases, one has to "... be in a dialogue again. There are these horribly boring tasks, technical ones, that you simply have to do. But when you realize that everyone does it, that volunteers aren't the ones who do all of the unpleasant work...", the volunteer realizes that this is just how it has to be and accepts it as a normal thing. However, I6-RC draws attention to the fact that "... awareness of the volunteers' possibilities and their adaptation, utilisation..." would allow the organisation to achieve better results. Volunteers' productivity is also promoted by the provision of the space for their self-fulfilment, "...as otherwise you can 'crush'..." the volunteer themself. Here again, the emphasis is on trust in the volunteer, which increases their motivation to complete the assigned tasks. However, as I6-RC explains, there are cases when "...the volunteer arrives and wants to introduce some radical change, but he fails. So, then you give him something and say: organize a celebration. And then he/she can do that celebration playing by his own rules...". I1-M singles out the volunteer's internal and external traits enabling him to be productive 
while working in the organisation: "...as to the volunteer himself/herself, I think one trait is curiosity. Curiosity to go and try. Also the goal, the goal to integrate, to become a part...". External matters are clear tasks and support. If this is fulfilled, the organisation can expect the volunteer who will fulfil their duties effectively. Nonetheless, I2-T and I6-RC conclude that not 50, but 80 per cent of success in volunteering depends on motivation and the very volunteer's preparation, while external support constitutes just 20 per cent.

Summarizing the informants' responses, the distinguished main factors or sub-categories are presented in Table 8.

Table 8. Work productivity of volunteers.

\begin{tabular}{cl}
\hline $\begin{array}{c}\text { Sub-Categories } \\
\begin{array}{c}\text { Trust as mediator } \\
\text { between organisation } \\
\text { and volunteer }\end{array}\end{array}$ & $\begin{array}{l}\text { I1-M: “...there should be a relationship of respect and trust, so that they could be } \\
\text { useful to one another." }\end{array}$ \\
\hline $\begin{array}{c}\text { Motivating the } \\
\text { volunteer }\end{array}$ & $\begin{array}{c}\text { I1-M: “...as to external things, motivators are clarity, specific tasks in the beginning, } \\
\text { knowing that you don't have to rush." }\end{array}$ \\
\hline $\begin{array}{c}\text { Flexibility } \\
\text { I2-T: “...there has to be a very broad perspective, so that you'd be able to change, } \\
\text { and it's not like I've come and I need this and this, and if not, then it's only } \\
\text { demands, give me that, give me that ... Then this attitude of the volunteer becomes } \\
\text { a problem rather than help." }\end{array}$ \\
$\begin{array}{l}\text { Openness of the } \\
\text { volunteer } \\
\text { technical ones, that you simply have to do. But when you realize that everyone } \\
\text { does it, that volunteers aren't the ones who do all of the unpleasant work, then the } \\
\text { volunteer realizes that this is just how it has to be and accepts it as a normal thing." }\end{array}$ \\
$\begin{array}{l}\text { I3-T: “...we take into account and encourage it a lot, we have the funds intended for } \\
\text { their monthly initiatives. They can decide where to take children after discussing } \\
\text { with the kindergarten employees or organize an activity, e.g., introduce our clients } \\
\text { to their traditional food." }\end{array}$ \\
\hline
\end{tabular}

Thus, in this context, importance is attached to mutual trust between the volunteer and the receiving organisation. After all, in addition to the volunteer's traits exhibiting emotional intelligence, a vital role is also played by the organisation that receives him and has to provide rather multifaceted support to him. To increase the volunteer's work productivity, it is imperative to introduce the volunteer to the organisation's activities, regulations and the target group. The volunteer's assessment and the feedback provided to them also positively influence their work productivity. Even so, the volunteer must be accompanied at the receiving organisation and meet the organisation's responsible persons to reflect on their experiences, receive feedback, seek problem-solving methods and plan their activities. The volunteer also has to be given freedom of self-expression while conducting their activities.

According to Qi et al. [69], cultural intelligence leads to an enhanced experience, while a lack of intercultural effectiveness leads to challenges, which again confirms the need for intercultural education. Volunteering, the volunteer's intercultural competence and emotional intelligence contribute to intercultural education and sustainability in various societies of today, because development of interculturality must be the means of enhancing sustainability of social and cultural development.

\section{Conclusions}

We propose a systematic perspective on the impact of emotional intelligence on work productivity, links between intercultural competence and work productivity, and the role played by emotional intelligence and intercultural competence in relation to volunteers working in foreign cultures. In most studies, these subjects are analysed separately; however, the organisations accepting volunteers need clear and simple tools enabling them to increase volunteer work productivity and improve quality of interactions while avoiding misunderstandings and supporting good psychosocial environment as 
well as wellbeing of the volunteers themselves. As a result, we identified the factors that could ensure this. These factors were established after modifying and empirically correcting the sub-categories created during the theoretical research. Using this method, it is possible to highlight the interactions between emotional intelligence, work productivity and volunteers' intercultural competence. Here, the crucial aspect is emotional intelligence, which in some sense serves as the mediator between the volunteer's intercultural competence and work productivity, when the volunteer-receiving organisations understand the role of emotional intelligence and devote attention to its development by introducing mentors. The latter can help volunteers to develop their emotional intelligence, which creates conditions for them to better integrate into the culture largely unfamiliar to the volunteer and also to increase their work productivity and ensure healthy psychological state. This demonstrates that volunteer-receiving organisations should focus on the growth of their employees' emotional intelligence. While volunteering abroad, emphasis should be placed on the volunteer's ability to recognize their own and others' emotions and appropriately use the aforementioned skills. This is especially vital while working with vulnerable target groups of the foreign culture, where the volunteer must possess fundamental social skills, the abilities to observe the environment and reflect on their experience. If the volunteer lacks these skills, he can learn them with the help of the receiving organisation. Emotionally strong volunteers can establish stronger relationships with clients and team members more quickly, which consequently makes it easier for them to integrate into the organisation and achieve the desired results.

This research presents a systematic perspective on the impact of emotional intelligence and intercultural competence on volunteers' work productivity. The results of this study could be useful to practitioners who organise volunteering activities and to the researchers who examine how emotional intelligence affects volunteers' work productivity. The results of this study also contribute to the expansion of the concept of intercultural education and sustainability.

The methodology of qualitative research does not provide the possibility to make far-reaching generalizations, whereas the conclusions of the study are based on the situation of one volunteer-receiving country. Our chosen systematic perspective and research results can be useful when conducting similar studies in other countries and also offer insights that could be utilised in international quantitative research focused on volunteers' work productivity.

Author Contributions: Conceptualization, J.V., R.B. and I.V.; formal analysis, J.V., R.B. and I.V.; data curation, I.V.; methodology, J.V. and I.V.; project administration, J.V.; investigation I.V.; resources I.V.; visualization, J.V., R.B. and I.V.; writing—original draft preparation, J.V., R.B. and I.V.; writing—review and editing, J.V., R.B. and I.V.

Funding: This research received no external funding.

Conflicts of Interest: The authors declare no conflict of interest.

\section{References}

1. Mangold, K. Struggling to do the right thing: Challenges during international volunteering. Third World Q. 2012, 33, 1493-1509. [CrossRef]

2. Furham, A. Culture Shock. J. Psychol. Educ. 2012, 7, 9-22.

3. Šimkus, A. Savanorystės žmogiškuju ištekliu valdymas: Nevyriausybiniu organizaciju Lietuvoje patirtis/Management of volunteering human resources: The experience of Lithuanian non-governmental organizations. Organizaciju Vadyba Sisteminiai Tyrimai/Manag. Organ. Syst. Res. 2015, 73, 83-104. [CrossRef]

4. Brudney, J.L.; Meijs, L.C.P.M. Models of volunteer management: Professional volunteer program management in social work. Hum. Serv. Organ. Manag. Leadersh. Gov. 2014, 38, 297-309. [CrossRef]

5. Lough, B.J. Social work perspectives on international volunteer service. Br. J. Soc. Work 2013, 44, 1340-1355. [CrossRef]

6. Navickas, V.; Simkus, A.; Strunz, H. The impact of volunteering as a form of leisure on students' life quality. Transform. Bus. Econ. 2016, 15, 96-112.

7. Kurapkaitienè, N. Darbo su Savanoriais Pagrindai; Mykolo Romerio Universitetas: Vilnius, Lithuania, 2013; 184p, ISBN 9789955195504. 
8. Ražanauskaitè, V. Savanoriškos veiklos organizavimas. In Socialinės Veiklos Organizavimas Bendruomenëje: Tinklaveika ir Savanoryste; Lietuvos Caritas: Kaunas, Lithuania, 2011; pp. 57-71.

9. Saulaitis, A. Savanorystès organizavimas bendruomeneje. In Socialinis darbas. Profesine veikla, metodai ir klientai; Mykolo Romerio Universitetas: Vilnius, Lithuania, 2010; pp. 223-246.

10. Mayer, J.D.; Salovey, P. What is emotional intelligence? In Emotional Development and Emotional Intelligence: Educational Implications; Salovey, P., Sluyter, J.D., Eds.; Basic Books: New York, NY, USA, 1997; pp. 3-31.

11. Brackett, M.A.; Rivers, S.E.; Salovey, P. Emotional intelligence: Implications for personal, social, academic, and workplace success. Soc. Personal. Psychol. Compass 2011, 5, 88-103. [CrossRef]

12. Koubova, V.; Buchko, A.A. Life-work balance: Emotional intelligence as a crucial component of achieving both personal life and work performance. Manag. Res. Rev. 2013, 36, 700-719. [CrossRef]

13. El-Chaarani, H. Exploring the impact of emotional intelligence on portfolio performance: An international exploratory study. Humanomics 2016, 32, 474-497. [CrossRef]

14. Bettis-Outland, H.; Guillory, M.D. Emotional intelligence and organizational learning at trade shows. J. Bus. Ind. Mark. 2018, 33, 126-133. [CrossRef]

15. Bacon, A.M.; Lenton-Maughan, L.; May, J. Trait emotional intelligence and social deviance in males and females. Personal. Individ. Differ. 2018, 122, 79-86. [CrossRef]

16. Gertsen, M.C. Intercultural competence and expatriates. Int. J. Hum. Resour. Manag. 1990, 1, 341-362. [CrossRef]

17. Byram, M. Teaching and Assessing Intercultural Communicative Competence; Multilingual Matters: Clevedon, UK, 1997.

18. Wilenius, M. Cultural competence in the business world: A Finnish perspective. J. Bus. Strategy 2006, 27, 43-49. [CrossRef]

19. Rice, M.F. A post-modern cultural competency framework for public administration and public service delivery. Int. J. Public Sect. Manag. 2007, 20, 622-637. [CrossRef]

20. Lloyd, S.; Hartel, C. Intercultural competencies for culturally diverse work teams. J. Manag. Psychol. 2010, 25, 845-875. [CrossRef]

21. Cai, D.Y. A concept analysis of cultural competence. Int. J. Nurs. Sci. 2016, 3, 268-273. [CrossRef]

22. Jyoti, J.; Kour, S. Cultural intelligence and job performance: An empirical investigation of moderating and mediating variables. Int. J. Cross Cult. Manag. 2017, 17, 305-326. [CrossRef]

23. Jamal, M. Type-a behaviour in a multinational organization: A study of two countries. Stress Health 2007, 23, 101-109. [CrossRef]

24. Randhawa, G. Work performance and its correlates: An empirical study. J. Bus. Perspect. 2007, 11, 47-55. [CrossRef]

25. Kallio, K.M.; Kallio, T.J. Management-by-results and performance measurement in universities-Implications for work motivation. Stud. High. Educ. 2014, 39, 574-589. [CrossRef]

26. Fleury, M.J.; Grenier, G.; Bamvita, J.M.; Farand, L. Relations between mental health team characteristics and work role performance. PLOS ONE 2017, 12, e0185451. [CrossRef]

27. Sujatha, R.; Krishnaveni, R. Knowledge creating ba as a determinant of work performance of employees: An empirical analysis among pump manufacturing firms in South India. Asia Pac. Manag. Rev. 2018, 23, 45-52. [CrossRef]

28. Kadic-Maglajlic, S.; Vida, I.; Obadia, C.; Plank, R. Clarifying the influence of emotional intelligence on salesperson performance. J. Bus. Ind. Mark. 2016, 31, 877-888. [CrossRef]

29. Cote, S.; Miners, C.T.H. Emotional Intelligence, Cognitive Intelligence, and Job Performance. Adm. Sci. Q. 2006, 51, 1-28. [CrossRef]

30. Tischler, L.; Biberman, J.; McKeage, R. Linking emotional intelligence, spirituality and workplace performance: Definitions, models and ideas for research. J. Manag. Psychol. 2002, 17, 203-218. [CrossRef]

31. Brief, A.P.; Weiss, H.M. Organizational Behavior: Affect in the Workplace. Ann. Rev. Psychol. 2002, 53, 279-307. [CrossRef] [PubMed]

32. Brackett, M.A.; Rivers, S.; Shiffman, S.; Lerner, N.; Salovey, P. Relating emotional abilities to social functioning: A comparison of performance and self-report measures of emotional intelligence. J. Personal. Soc. Psychol. 2006, 91, 780-795. [CrossRef]

33. Wong, C.S.; Law, K.S. The effects of leader and follower emotional intelligence on performance and attitude: An exploratory study. Leadersh. Q. 2002, 13, 243-274. [CrossRef] 
34. Law, K.S.; Wong, C.S.; Song, L.J. The construct and criterion validity of emotional intelligence and its potential utility for management studies. J. Appl. Psychol. 2004, 89, 483-496. [CrossRef]

35. Eisenberg, N. Emotion, regulation, and moral development. Ann. Rev. Psychol. 2000, 51, 665-697. [CrossRef]

36. Castro, F.; Gomes, J.; de Sousa, F.C. Do Intelligent Leaders Make a Difference? The Effect of a Leader's Emotional Intelligence on Followers' Creativity. Creat. Innov. Manag. 2012, 21, 171-182. [CrossRef]

37. Lucas, V.; Laschinger, H.K.S.; Wong, C.A. The impact of emotional intelligent leadership on staff nurse empowerment: The moderating effect of span of control. J. Nurs. Manag. 2008, 16, 964-973. [CrossRef]

38. Devonish, D. Emotional intelligence and job performance: The role of psychological wellbeing. Int. J. Workplace Health Manag. 2016, 9, 428-442. [CrossRef]

39. Guy, M.; Lee, H.Y. How Emotional Intelligence Mediates Emotional Labor in Public Service Jobs. Rev. Public Pers. Adm. 2015, 35, 261-277. [CrossRef]

40. Guy, M.E.; Newman, M.A.; Mastracci, S.H. Emotional Labor: Putting the Service in Public Service; M.E. Sharpe: Armonk, NY, USA, 2008.

41. Triandis, H.C. Cultural intelligence in organizations. Group Organ. Manag. 2006, 31, 20-26. [CrossRef]

42. Lee, L.Y.; Kartika, N. The influence of individual, family and social capital factors on expatriate adjustment and performance: The moderating effect of psychology contract and organizational support. Expert Syst. Appl. 2014, 41, 83-94. [CrossRef]

43. Huff, K.C. Language, cultural intelligence and expatriate success. Manag. Res. Rev. 2013, 36, 596-612. [CrossRef]

44. Lee, L.Y. Multiple intelligence and the success of expatriation: The roles of contingency variables. Afr. J. Bus. Manag. 2010, 4, 3793-3804.

45. Kumar, N.; Rose, R.C.; Subramaniam, S.R. The effects of personality and cultural intelligence on international assignment effectiveness: A review. J. Soc. Sci. 2008, 4, 320-328. [CrossRef]

46. Campbell, J.P. The definition and measurement of performance in the new age. In The Changing Nature of Performance: Implications for Staffing, Motivation and Development; Ilgen, D.R., Pulakos, E.D., Eds.; Jossey-Bass: San Francisco, CA, USA, 1999; pp. 399-429.

47. Jyoti, J.; Kour, S. Assessing the cultural intelligence and task performance equation: Mediating role of cultural adjustment. Cross Cult. Manag. 2015, 22, 236-258. [CrossRef]

48. Ang, S.; Van Dyne, L.; Koh, C.; Ng, K.Y.; Templer, K.J.; Tay, C.; Chandrasekar, N.A. Cultural intelligence: Its measurement and effects on cultural judgment and decision making, cultural adaptation and task performance. Manag. Organ. Rev. 2007, 3, 335-371. [CrossRef]

49. Ochieng, E.G.; Price, A.D. Framework for managing multicultural project teams. Eng. Constr. Archit. Manag. 2009, 16, 527-543. [CrossRef]

50. Brett, J. Intercultural challenges in managing workplace conflict-A call for research. Cross Cult. Strateg. Manag. 2017, 25, 32-52. [CrossRef]

51. Ghosh, A. Interpersonal Cross-Cultural Contact Exploring the Role of Cultural Encounters as Antecedent to Cultural Competence at Workplace. Manag. Labour Stud. 2013, 38, 81-101. [CrossRef]

52. Appelbaum, S.H.; Shapiro, B.; Elbaz, D. The management of multicultural group conflict. Team Perform. Manag. Int. J. 1998, 4, 211-234. [CrossRef]

53. Dusi, P.; Messetti, G.; Steinbach, M. Skills, attitudes, relational abilities \& reflexivity: Competences for a multicultural society. Procedia Soc. Behav. Sci. 2014, 112, 538-547. [CrossRef]

54. Kenesei, Z.; Stier, Z. Managing communication and cultural barriers in intercultural service encounters: Strategies from both sides of the counter. J. Vacat. Mark. 2017, 23, 307-321. [CrossRef]

55. Pruskus, V. Kompetencijų vaidmuo sprendžiant tarpkultūrinius konfliktus/The role of competencies while solving intercultural conflicts. Logos Vilnius 2011, 67, 142-152.

56. Terry, J. Motivating a multicultural workforce. Ind. Commer. Train. 2007, 39, 59-64. [CrossRef]

57. Moon, T. Emotional intelligence correlates of the four-factor model of cultural intelligence. J. Manag. Psychol. 2010, 25, 876-898. [CrossRef]

58. Earley, P.C.; Ang, S. Cultural Intelligence: An Analysis of Individual Interactions across Culture; Stanford University Press: Palo Alto, CA, USA, 2003.

59. Clark, J.M.; Polesello, D. Emotional and cultural intelligence in diverse workplaces: Getting out of the box. Ind. Commer. Train. 2017, 49, 337-349. [CrossRef]

60. Cassell, C. A fatal attraction? Strategic HRM and the business case for women's progression. Pers. Rev. 1996, 25, 51-66. [CrossRef] 
61. Jackson, S.E.; Joshi, A. Diversity in social context: A multi-attribute, multilevel analysis of team diversity and sales performance. J. Organ. Behav. 2004, 25, 675-702. [CrossRef]

62. Antonakis, J.; Ashkanasy, N.; Dasborough, M.T. Does leadership need emotional intelligence? Leadersh. Q. 2009, 20, 247-261. [CrossRef]

63. Zhou, J.; George, J.M. Awakening employee creativity: The role of leader emotional intelligence. Leadersh. $Q$. 2003, 14, 545-568. [CrossRef]

64. Chua, R.Y.J.; Roth, Y.; Lemoine, J.F. The impact of culture on creativity: How cultural tightness and cultural distance affect global innovation crowdsourcing work. Adm. Sci. Q. 2015, 60, 189-227. [CrossRef]

65. Lilis, M.P.; Tian, R.G. Cross-cultural communication and emotional intelligence: Inferences from case studies of gender diverse groups. Mark. Intell. Plan. 2009, 27, 428-438. [CrossRef]

66. Tan, J.A.C.; Härtel, C.E.J.; Panipucci, D.; Strybosch, V.E. The effect of emotions in cross-cultural expatriate experiences. Cross Cult. Manag. Int. J. 2005, 12, 4-15. [CrossRef]

67. Braun, V.; Clarke, V. Using thematic analysis in psychology. Qual. Res. Psychol. 2006, 3, 77-101. [CrossRef]

68. Schreier, M. Qualitative content analysis. In The SAGE Handbook of Qualitative Data Analysis; SAGE Publications Ltd.: Thousand Oaks, CA, USA, 2014. [CrossRef]

69. Qi, H.X.; Smith, K.A.; Yeoman, I. Cross-cultural event volunteering: Challenge and intelligence. Tour. Manag. 2018, 69, 596-604. [CrossRef]

(C) 2019 by the authors. Licensee MDPI, Basel, Switzerland. This article is an open access article distributed under the terms and conditions of the Creative Commons Attribution (CC BY) license (http://creativecommons.org/licenses/by/4.0/). 